\title{
USE OF FACEBOOK FOR LEARNING AND ASSESSMENT IN GEOGRAPHY
}

\author{
MARIA ELIZA DULAMĂ \\ Babeş-Bolyai University, Faculty of Psychology and Sciences of Education, Cluj-Napoca, Romania, \\ e-mail:dulama@upcmail.ro
}

STANCA VESCAN

"Iulian Pop" Economic High School, Cluj-Napoca, Romania, e-mail: vescan_stanca@yahoo.com

\section{IOANA MAGDAȘ}

Babeş-Bolyai University, Faculty of Psychology and Sciences of Education, Cluj-Napoca, Romania, e-mail: magdas_ioana@yahoo.com

(Received: December 2015; in revised form: February 2016)

\begin{abstract}
In this research was analysed 120 twelfth grade students' behaviour, of "Iulian Pop" Economic High School in Cluj-Napoca, Romania, regarding the use of the Facebook social network for learning and assessment in Geography. Students were organised in five discussion groups on the social network Facebook. To achieve the research objectives, we analysed students' answers at a questionnaire and the contents of the dialogue between teacher and students and also between students. Students perceived positively the learning and assessment activities and they perceived their teacher as their equal. At the cognitive level, the activity was focused on clarifying certain aspects, revision, knowledge learning and assessment. The disadvantages of the learning activity in the Facebook discussion group were that the posted materials cannot be classified and can be found with difficulty.
\end{abstract}

Keywords: learning communities, e-learning, virtual learning, social media 


\section{INTRODUCTION}

Facebook is currently the largest worldwide virtual community with over 800 million users (Socialbakers, 2012). Romania had 8.3 million Facebook users in December 2015, 33.12\% of them between 15 to 24 years old (Facebook Romania Demographics Data, http://www.facebrands.ro/demografice.html). In 2016, there are 250,040 Facebook users in Cluj-Napoca (3.22\% of the total users in Romania), being the third city in the country by number of users (Map of Facebook users in Romania, http://www.facebrands.ro/demografice.html). Many Romanian educational institutions have official or unofficial Facebook pages, which are managed by students, teachers or by others.

Online social networks such as Facebook offer attractive means for interaction and communication, but also raise privacy and security concerns (Acquisti and Gross, 2006). Social Networking Sites (SNS) such as Facebook are among the latest examples of communications technologies that have been widely-adopted by students and, consequently, have the potential to become a valuable resource to support their educational communication and collaboration with their faculty. However, faculty members have a track record of prohibiting classroom uses of technologies that are frequently used by students (Roblyer et al., 2010).

Educators and others are interested in the effects of social media on high school students, on the time spent preparing for classes, and on thd time spent in co-curricular activities (Junco, 2012). The Facebook social network is used as a tool to organise informal student study groups for training and collaboration (Ellison et al., 2007). These researchers analysed the types of communication between students and instructors, and the social and psychological factors influencing its use. Other studies targeted the duration of use, its purpose, and how the Facebook network is used. Pempek et al. (2009) argued that students use daily the Facebook for about 30 minutes to express their identity, for social interaction, using a one-tomany style in which they were the creators, disseminating content to their friends, in particular, with previously known friends. British undergraduate students thought, in 2009, that Facebook was used most importantly for social reasons, not for formal teaching purposes, although it was sometimes used informally for learning purposes (Madge et al., 2009).

Hew (2011) suggested that Facebook had been very little used for education so far, that students used Facebook mainly to keep in touch with known individuals, and that they tended to disclose more personal information on Facebook, hence attracting potential privacy risks upon themselves. 
Grosseck et al. (2011) noted that Facebook had become an important part of students' life, as the majority of them spent significantly more time for social use (e.g. for contact with friends and family, to share photos/tag, to engage in social activism, volunteering, etc.) and less for academic purposes, although they discussed assignments, lectures, study notes, or exchanged information on research resources. They said that many university professors argued that Facebook could be used for many purposes in academic education (formal).

In Romania, all surveyed Geography students in Cluj-Napoca used the Facebook for communication. A third of them said they spent 4-6 hours on the Internet daily. Over $75 \%$ of them used the Internet much or very much for personal purposes (for information, documentation, viewing, games). They were active on Facebook where they studied the posted materials, communicated with friends and promoted some materials (Dulamă et al., 2015b). This use was facilitated by the fact that, in the context of Web 2.0, students "can gain access to information according to their vocation, needs, pace and learning style, etc." (Osaci-Costache et al., 2014, p. 219). Mobile devices (smartphone, tablet, etc.) facilitated accessing online data at any time, provided there was an Internet connection (Osaci-Costache et al., 2014, p. 218)

The surveyed Geography students in Cluj-Napoca formed a Facebook active learning community on solving Geography problems, discuss Geography issues, organised geographical events, reading and viewing geographical materials and promoting the most interesting of them (Dulamă et al., 2015a).

Considering students' behaviour and interest for Facebook and the fact that social networking can be an effective/strong cooperative learning and organisational management, researchers said that professors and teachers got more involved into building the academic community learning related to their courses.

Recognising the impact of the Facebook on young people, they underlined the following problem: How could this information and communication virtual environment be capitalised in high school education for increasing the learning effectiveness and to form and develop Geography specific skills?

The objectives of this research were:

1) analysing high school students' behaviour in Geography discussion group on Facebook;

2) analysing the use of Facebook in learning and assessment within formal and informal activities in a group discussion.

The results of this research will be useful in rethinking learning activities at the high school and university level. 


\section{MATERIAL AND METHOD}

\section{Population}

This research focused on a behaviour analysis for five Geography discussion groups consisting of 120 twelfth grade students of "Iulian Pop" Economic High School, in Cluj-Napoca, Romania, in the 2015-2016 school year. These students represented the total student population who attended the "Geography of Romania, of Europe and of the European Union" course during that school year. $90 \%$ of those students had chosen that discipline for the baccalaureate exam.

\section{Research material}

It consists of students' answers at a questionnaire and the content of the dialogue between teacher and students, and also between the students organised in five discussion groups on Facebook. The questionnaire contained 12 multiple choice items. Four items required choosing an answer from a list and eight items allowed multiple choice answers.

\section{Procedures}

The questionnaire was offered in print and students filled it voluntarily, anonymously, so we could not correlate their responses with students' academic achievement in Geography.

\section{RESULTS AND DISCUSSIONS}

The analysis of students' responses to the questionnaire

By analysing students' responses regarding the time spent for socialising on Facebook, we noticed that it was a lot compared to the number of hours of school (5-6 hours) (Figure 1). One third of the students alloted 1-2 hours daily for this purpose, while a quarter of them alloted 2-4 hours. A small number of students $(6.7 \%)$ said they used Facebook more than 6 hours, which is a lot. Because students were very strongly attracted to the Facebook, secondary school teachers should be concerned about using social media for educational purposes. 


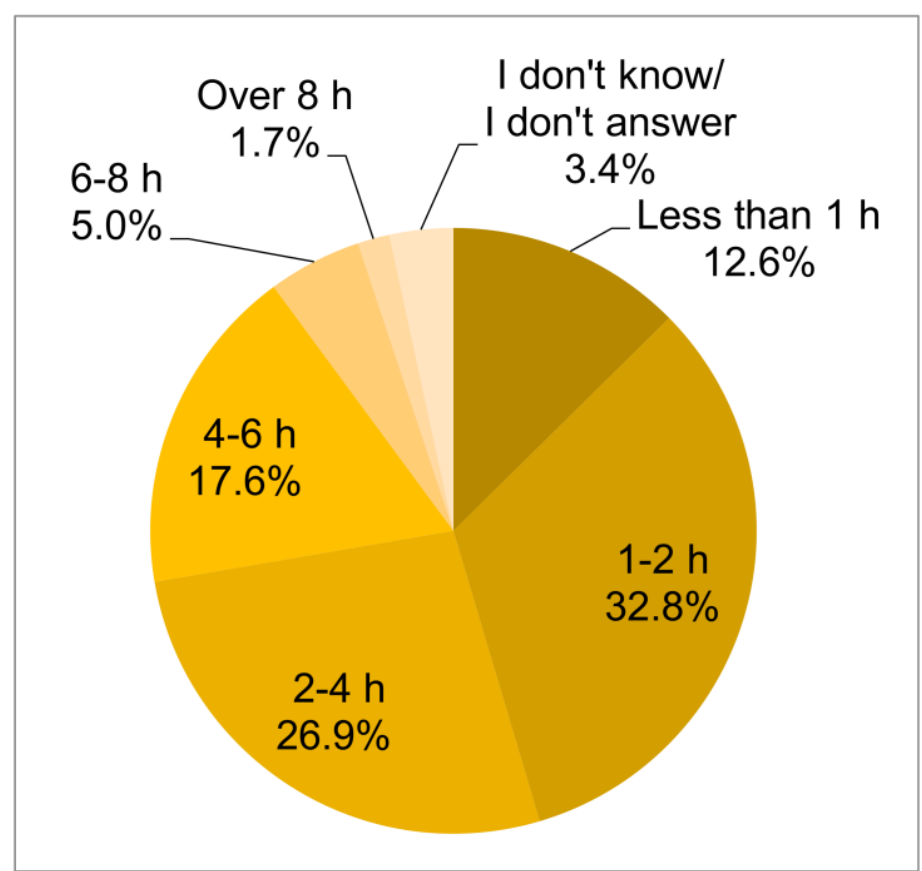

Fig. 1. Number of hours students spent daily on Facebook

Most students used Facebook at home (Figure 2). The fact that only very few used Facebook at school, indicated that either they did not have Internet access on their mobile phones or they were concerned about the formal activities performed at school.

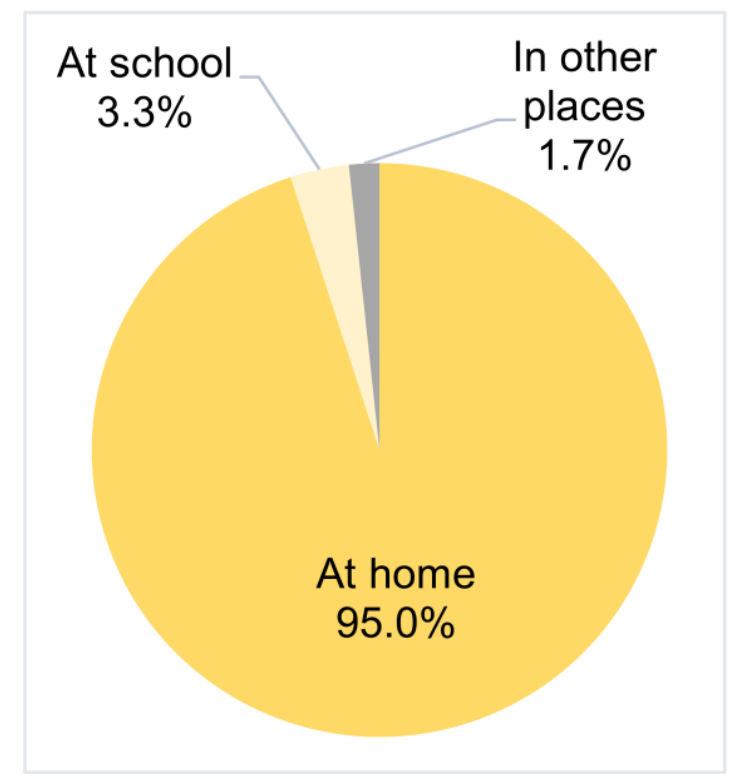

Fig. 2. Locations where students accessed Facebook 
In the frequency of accessing Facebook discussion group to learn Geography (Figure 3), a third of the students did that twice a week, probably connected with the two hours a week scheduled in their timetable. The fact that over $38 \%$ of the students accessed the discussion group at least three times per week showed these students' great interest for Geography. The fact that less than a quarter accessed their discussion group once a week correlated with those students who did not answer. We concluded that about $30 \%$ of these students were less interested in Geography. In addition, $70 \%$ of the students showed high and very high interest for Geography study.

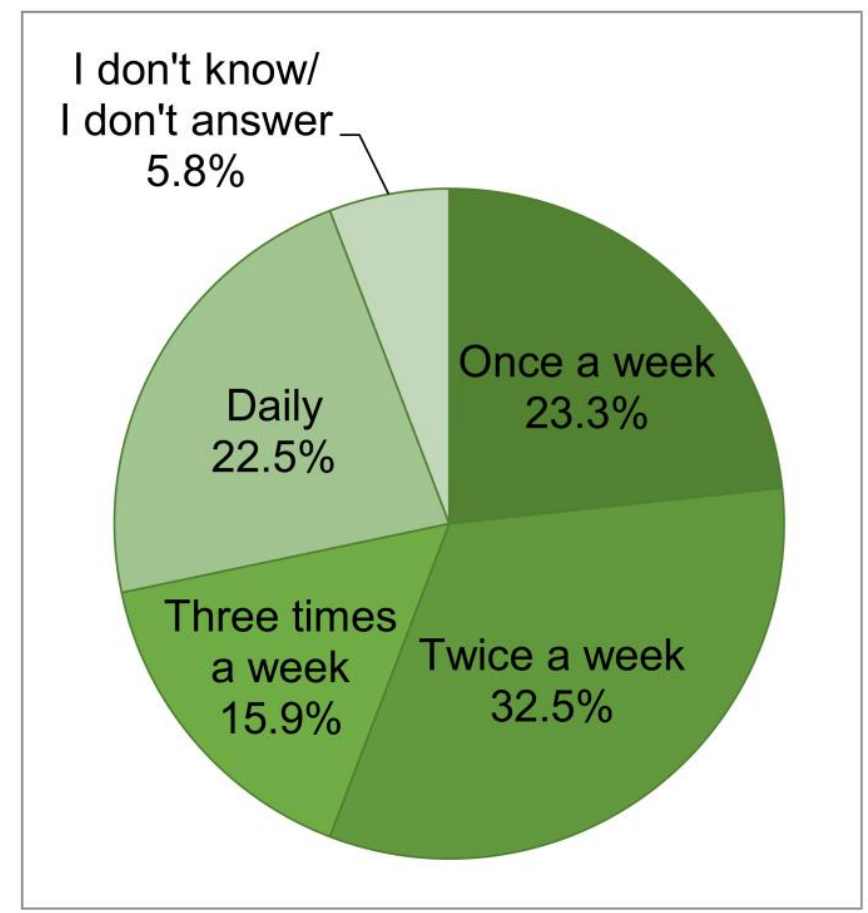

Fig. 3. Students' frequency of accessing

the Geography discussion group on Facebook

When accessing the discussion group on Facebook, to learn Geography, half of the students said their work lasted less than 30 minutes (Figure 4). Less than half said that their work lasted 30-60 minutes. Considering that $12^{\text {th }}$ grade students stayed at school 5-6 hours daily and that for every day they had to solve various tasks at home, then assigning 30 minutes for that activity was consistent with reality. 


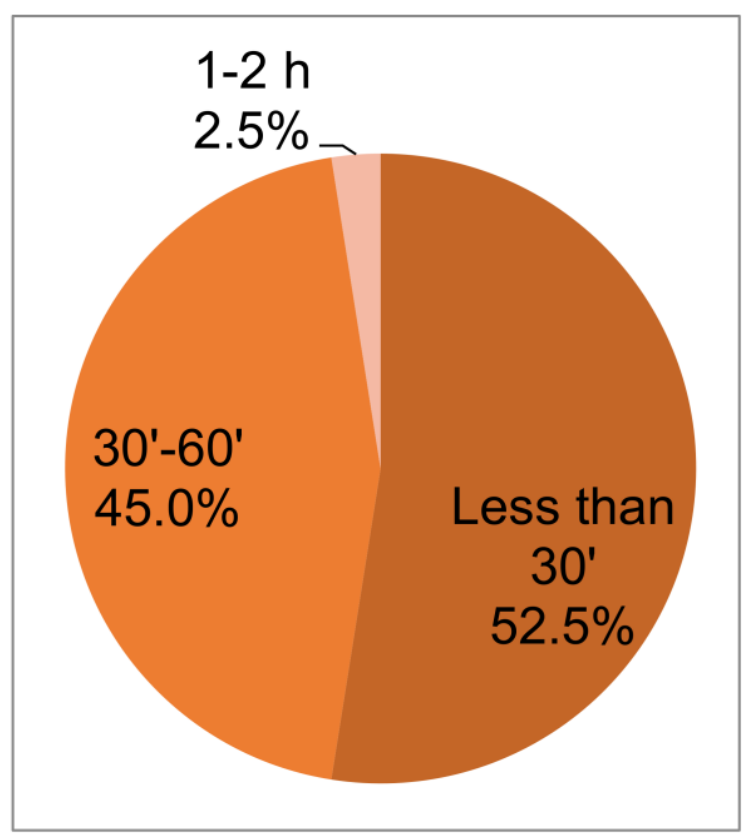

Fig. 4. The length of time students spent in the Geography discussion group

A high percentage of students (74.2\%) argued that they used smart phones/mobiles, and almost half of them used personal computers to access the Facebook discussion group on Geography (Figure 5). Those values indicated they had fast Internet access via the phone because in various places in the city internet was wireless. Because they said that they accessed Facebook mostly from home, we expected to make the connection through the computer, not by phone. We noticed that over one third of the students had accessed their Facebook discussion group through personal laptops and just $20 \%$ by using tablets. There was undoubtly weak interest for using tablets to access the Internet and Facebook although tablets were recommended in the education system in Romania at ministerial level. The least used way for accessing Facebook was that of school computers, which were located in the Computer Science labs.

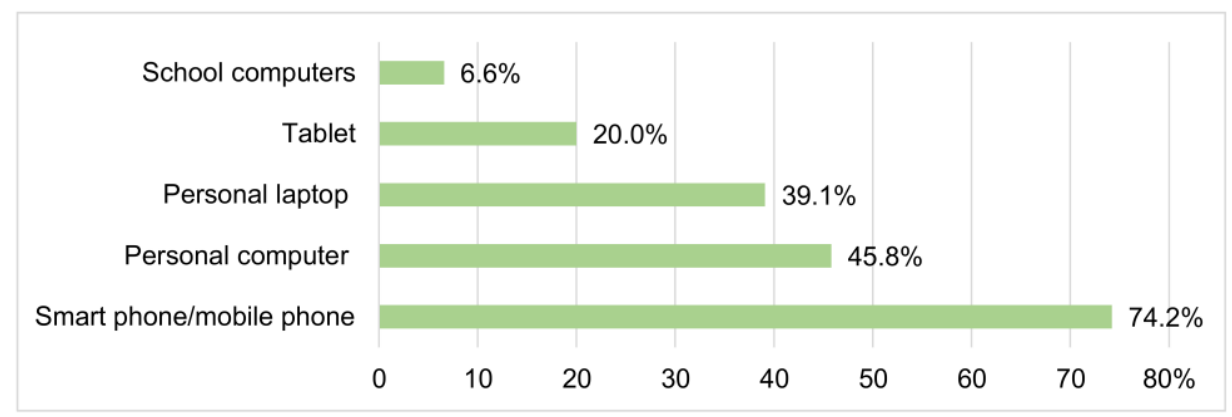

Fig. 5. Devices that students used to access

the discussion group and their frequency 
The most popular materials studied by students on Facebook group discussions were photos and maps, which over $75 \%$ of students viewed (Figure 6). This preference was similar to the Geography students, of which $82.1 \%$ studied frequently on Facebook photos with geographical contents and $67.9 \%$ of them studied maps (Dulamă et al., 2015). Students' interest was lower for texts and for sites containing geographical video games because only a third of them said they studied such materials. Almost one third of the students said that they studied sketch maps made by colleagues and Geography tests solved by the others. Interest in studying these materials was explained through the fact that those materials enabled learning. Students showed less interest in studying Geography documentaries, pages containing geographical contents, and geographical PowerPoint presentations. The fact that $1.6 \%$ of the students said they studied Geography animations was due to the fact that those materials were less promoted on social networks, although in 2016 there was this trend.

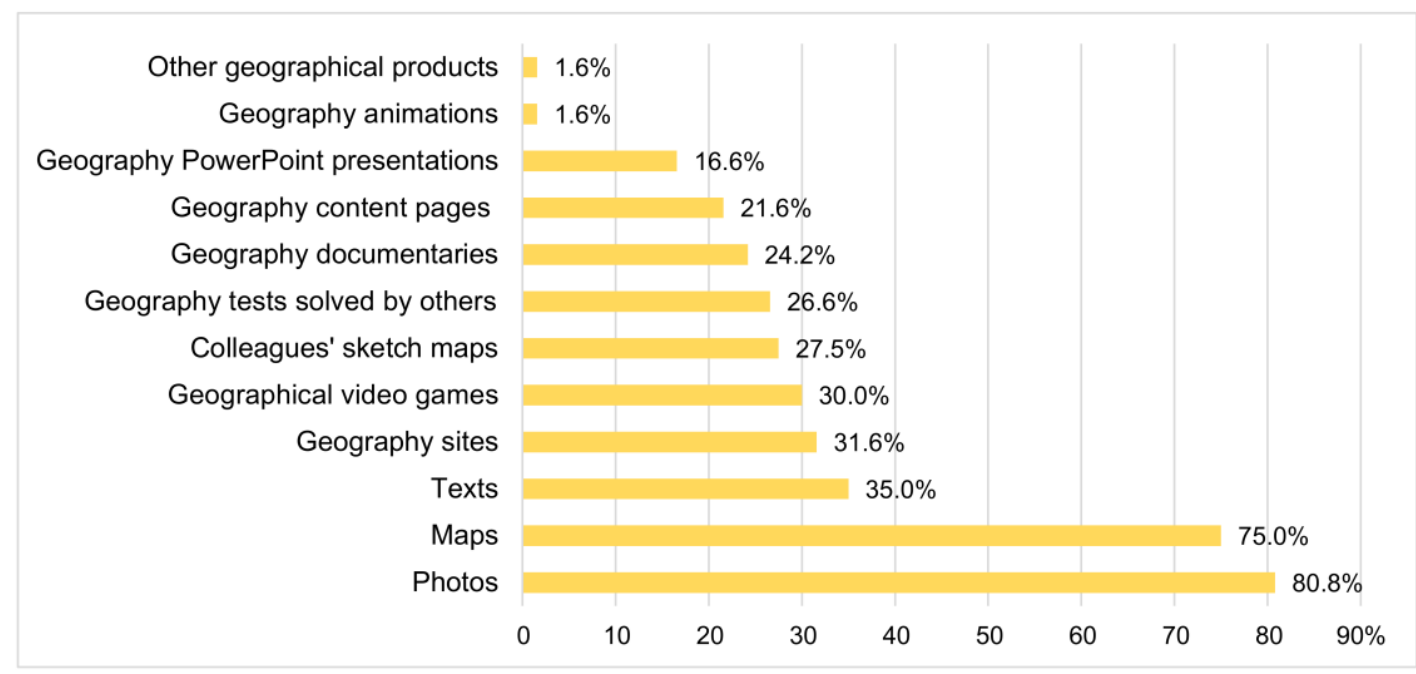

Fig. 6. Type and frequency of materials studied by students, which were posted by their teacher or by colleagues

Regarding the materials created by students and posted in the discussion group, we noticed that for each type of material values were below $40 \%$ (Figure 7). A third of the students said they had posted on the Facebook discussion group solved Geography tests and Geography texts. This fact indicated their interest in assessing knowledge. A quarter of the students posted Geography photos and sketch maps taken with their cell phones. Only $5 \%$ of them posted Geography PowerPoint presentations. $5 \%$ of the 
students posted other products with geographical contents, but did not specify what. Those probably included geographical jokes or games. Those values indicated a smaller involvement that could be explained by the fact that students were in the first semester of the school year and was less than three months since the discussion group had been formed.

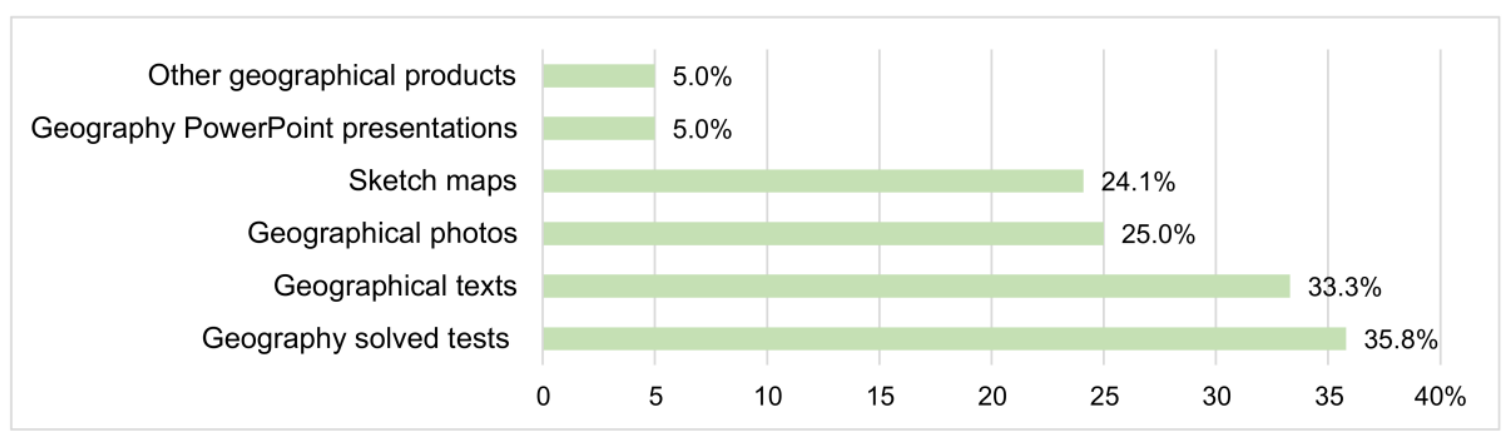

Fig. 7. Type and frequency of the posted materials created by students

Regarding the distribution of the Geography materials on the Facebook discussion group, we noticed students' preference for maps (Figure 8). The fact that $38.3 \%$ of the students said they had forwarded maps indicated the importance of maps in learning Geography and students realised that. On the next places in the hierarchy of forwarded materials, with close rank values, were geographical photos and texts, followed by Geography tests. Those materials were forwarded by approximately $25 \%$ of the students. $17.5 \%$ of the students forwarded sketch maps. The fact that students forwarded those materials indicated that they considered them important for learning Geography and for assessment.

Less distributed by students (below 7\%) were geographical video games, geographical sites, Geography documentaries, Geography pages, Geography animations, and Geography PowerPoint presentations. The fact that students forwarded rarely video games and geographical animations was because of the small number of such products on Facebook. On the Internet, there were many such products in various languages, but less in Romanian. Although on Facebook there were many pages with Geography contents and there were promoted various Geography websites, it seemed that high school students, unlike university Geography students (Dulamă et al., 2015) were less concerned with those contents. Therefore, we noticed that students focused on the materials they considered relevant for their baccalaureate exam training and less on other materials containing Geography.

Regarding the materials downloaded from the Facebook discussion group, students' interest in the same materials, as in the case of forwarding, stood out (Figure 9): geographical photos, maps, texts containing Geography, Geography tests, and sketch maps. We believed that students preferred to download those materials in their own computer for organising in categories and finding them easily when they needed them. 


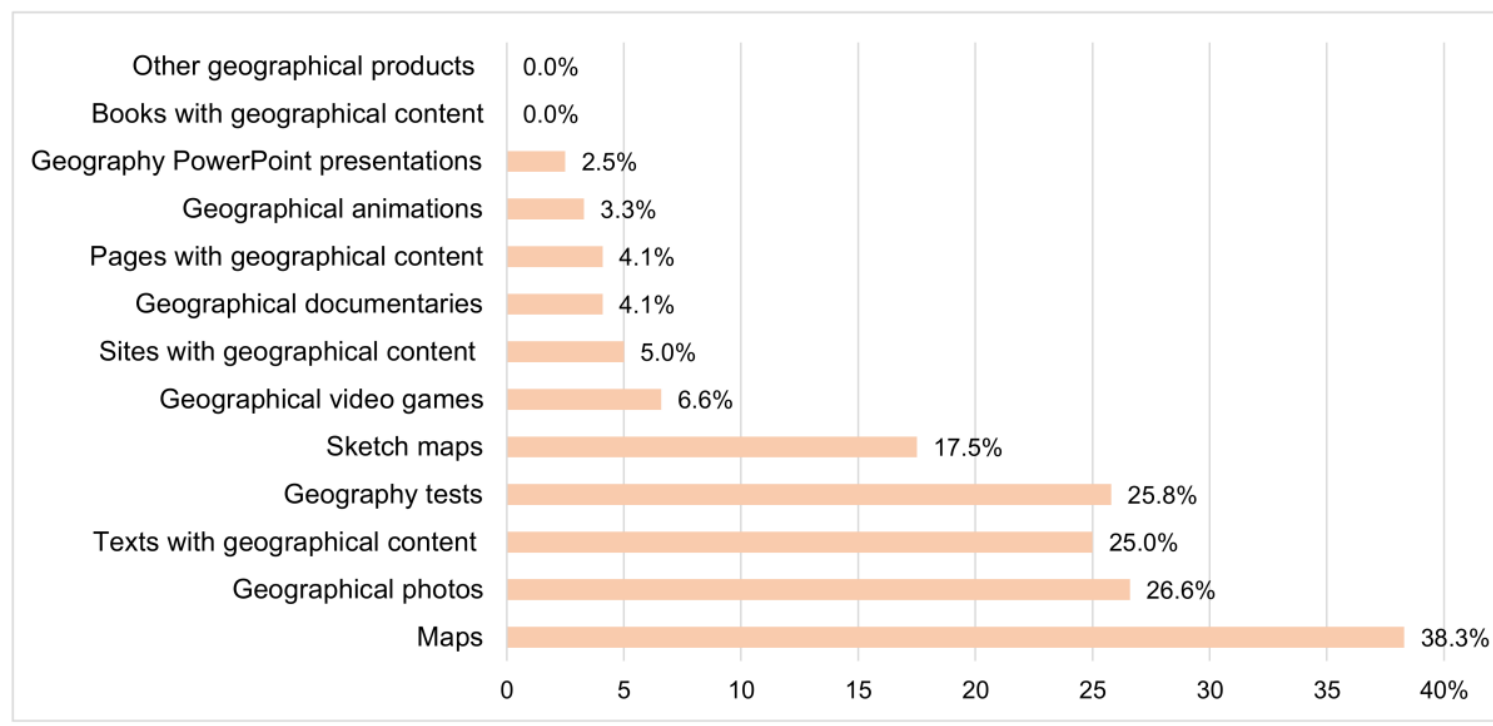

Fig. 8. Type and frequency of the forwarded materials in the Geography discussion group on Facebook

Because Facebook does not offer facilities for grouping materials or finding them easily when needed is a disadvantage for individual and group learning. The fact that students downloaded only a few geographical documentaries, Geography PowerPoint presentations, books with geographical contents, and geographical animations was because those were less promoted on Facebook, so students had not discovered and forwarded them yet.

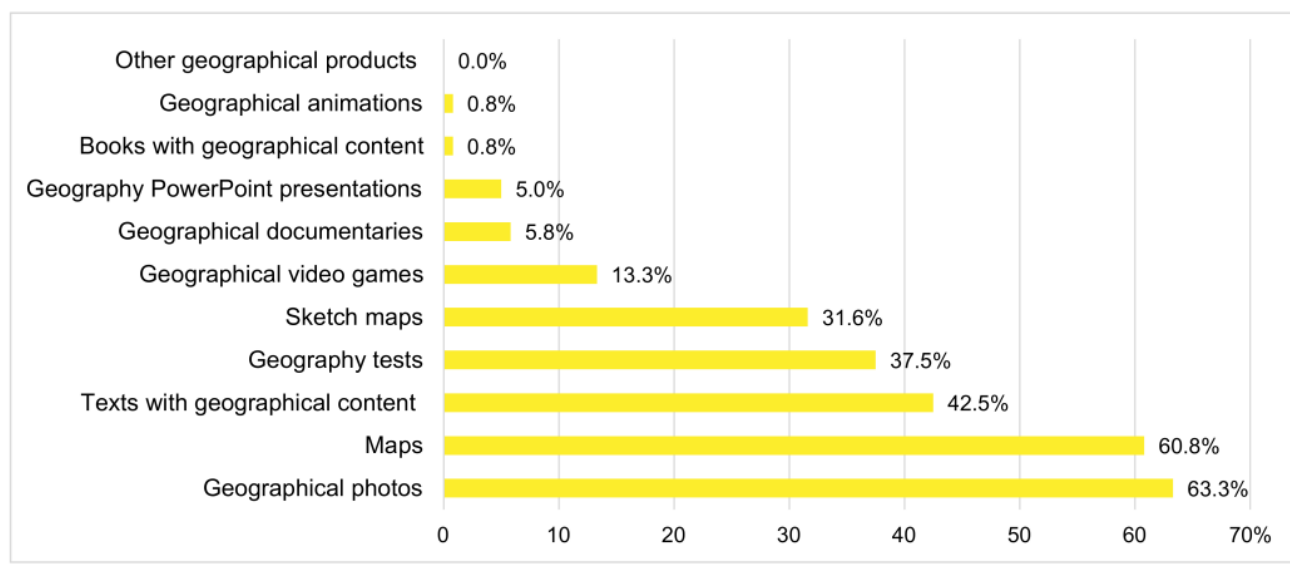

Fig. 9. Type and frequency of the downloaded materials from the Geography discussion group on Facebook 
In Figure 10, we represented the frequency of activities developed by students in the Geography discussion group on Facebook. For over half of students, the main activity was self-evaluation, the main form of assessment being, in fact, to respond at questions posted by teacher or by classmates. That third of the students asked by colleagues indicated their interest either for finding answers or for co-operating with colleagues in learning and knowledge assessment. The fact that almost a quarter of the students said they assessed their colleagues' responses and offered emoticons, indicated also their degree of involvement in evaluation. We observed students' preference for using emoticons to provide a feedback at their colleagues' answers. The fact that only $19.1 \%$ of the students said they read classmates' assessments seemed not to be plausible because each person should have been preoccupied with the result of his or her performance evaluations. We noticed that only $9.1 \%$ of the students asked their teacher to question them and even less of them $(7.5 \%)$ required some explanations from their teacher within the Geography discussion group. Only a few students asked their colleagues to clarify certain aspects $(6.6 \%)$. We have several explanations for this behaviour: they did not need learning support, they did not want to disturb other people or they did not want to show ignorance.

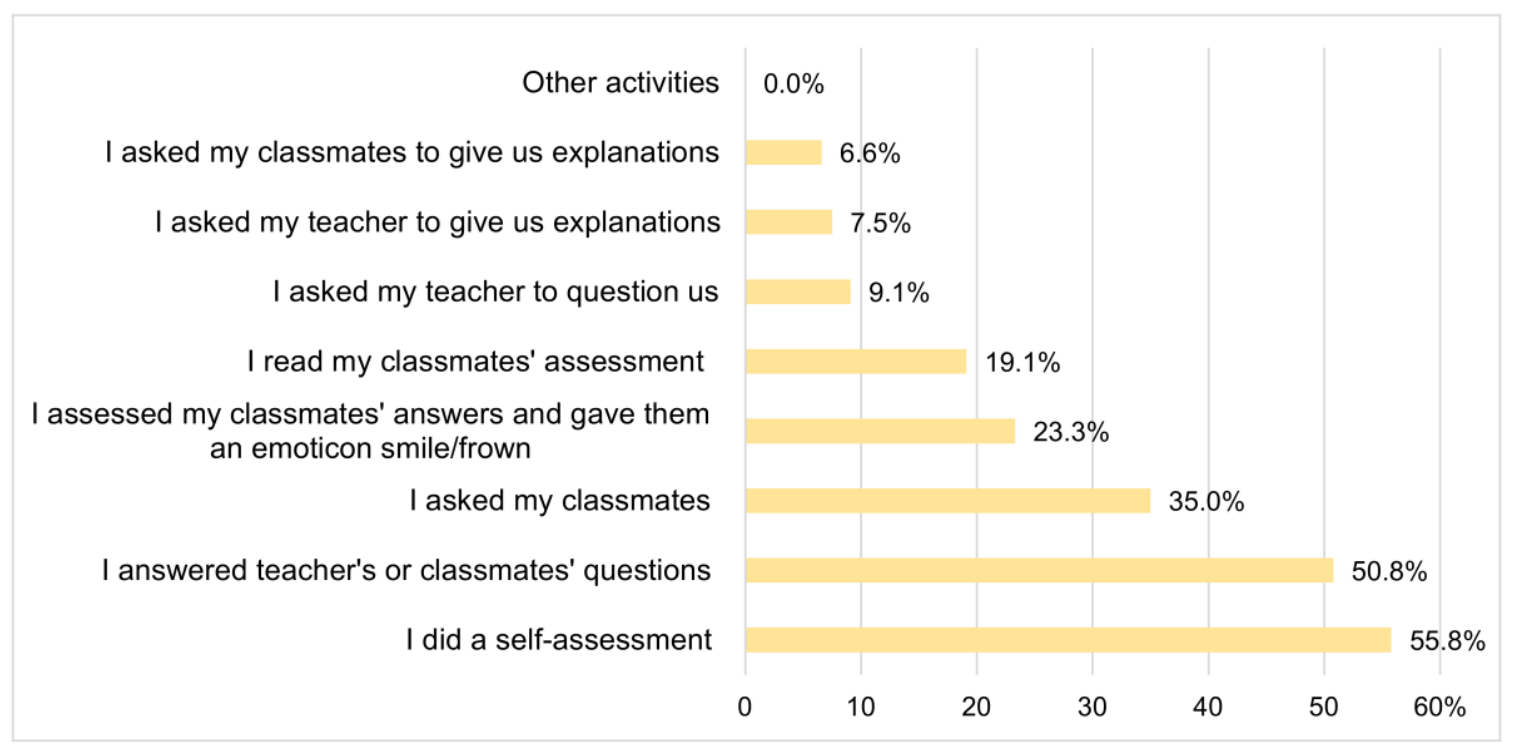

Fig. 10. Frequency of activities developed by students in the Geography discussion group on Facebook

We surveyed students about reasons why they liked to operate learning activities on the Geography discussion group on Facebook (Figure 11). Those reasons were associated with cognitive and emotional processes that students performed in discussion group activities. $54.2 \%$ of them liked those because they reviewed information, and half of them got aware of 
what they knew and did not know. Over $40 \%$ of them liked that the teacher always encouraged them and almost $20 \%$ of them felt challenged, really motivated to get involved also when they were tired, which was very good. Students made differences between various activities through which they kept in mind knowledge. Thus, $30 \%$ said that they memorised details better, $40 \%$ said that they learnt better by answering/solving a task, and $27.5 \%$ of them memorised more easily the position of places on the map. Students perceived correctly the role of group activities in the awareness process, memorisation and information consolidation and much less in their systematisation, which was difficult to achieve on Facebook. A small number of students stated they learnt to solve quickly and accurately the tasks and to understand what was required, presumably because the tasks given were clear and with a low difficulty level.

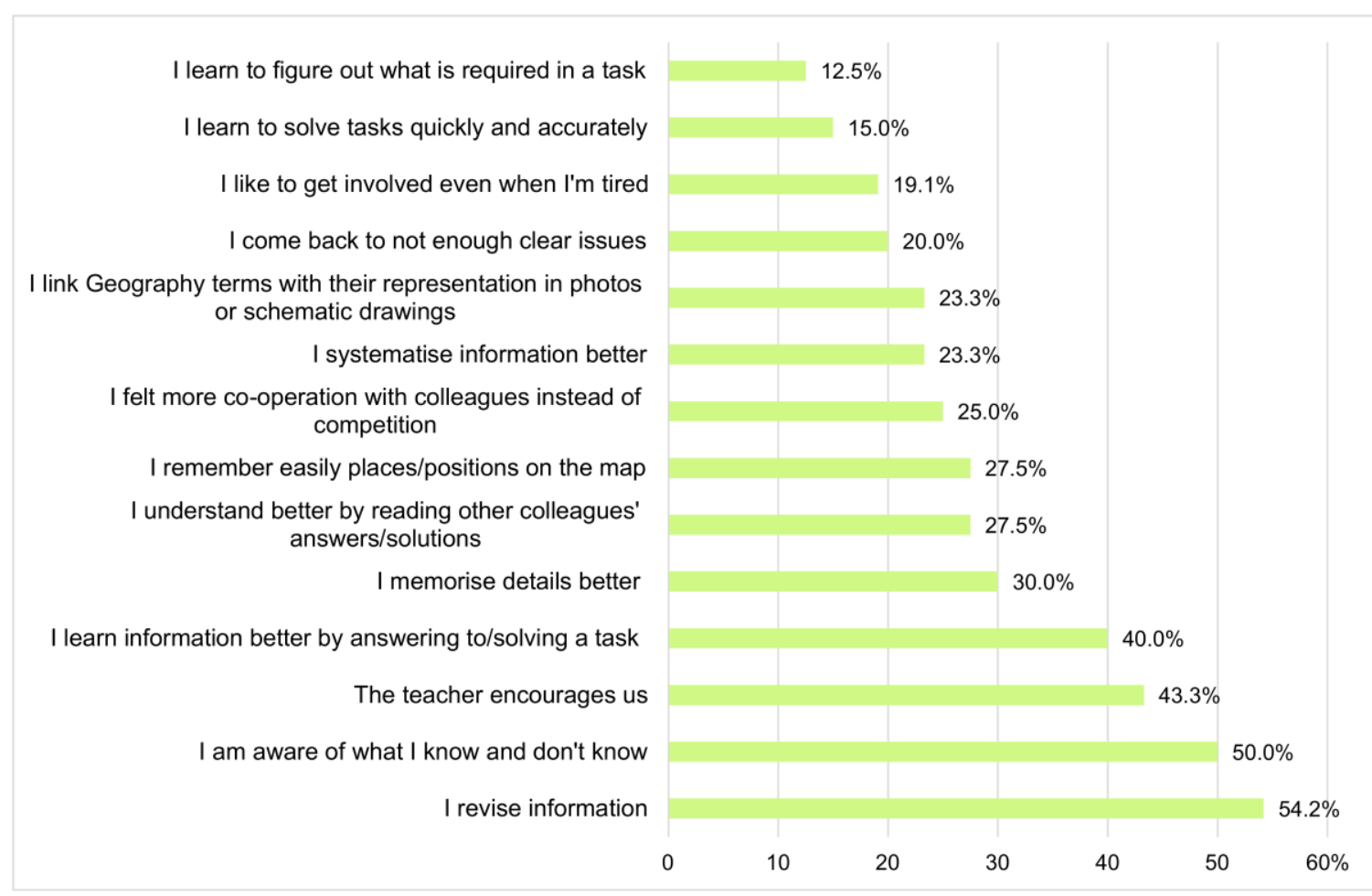

Fig. 11. Frequency of reasons why students liked to operate learning activities in the Geography discussion group on Facebook

In Figure 12, we represented the reasons why students liked to operate assessment activities in the Geography discussion group on Facebook. The fact that nearly $60 \%$ of the students said that they liked to carry out the assessment on group discussions because they felt it beneficial indicated 
they correlated assessment with learning. The fact that nearly half of the students liked this kind of evaluation because they did not receive grades indicated they felt pressure when receiving grades. Almost half of the students liked the option to write a task solution only if they wanted it and appreciated the fact they saw other colleagues' answers/solutions. $44.2 \%$ of the students appreciated they found quickly if the answer/solution was correct, and $38.3 \%$ that they underwent assessment outside school hours and that this had no official character. Overall, we saw that over $40 \%$ of the students liked to be evaluated within the discussion group on Facebook.

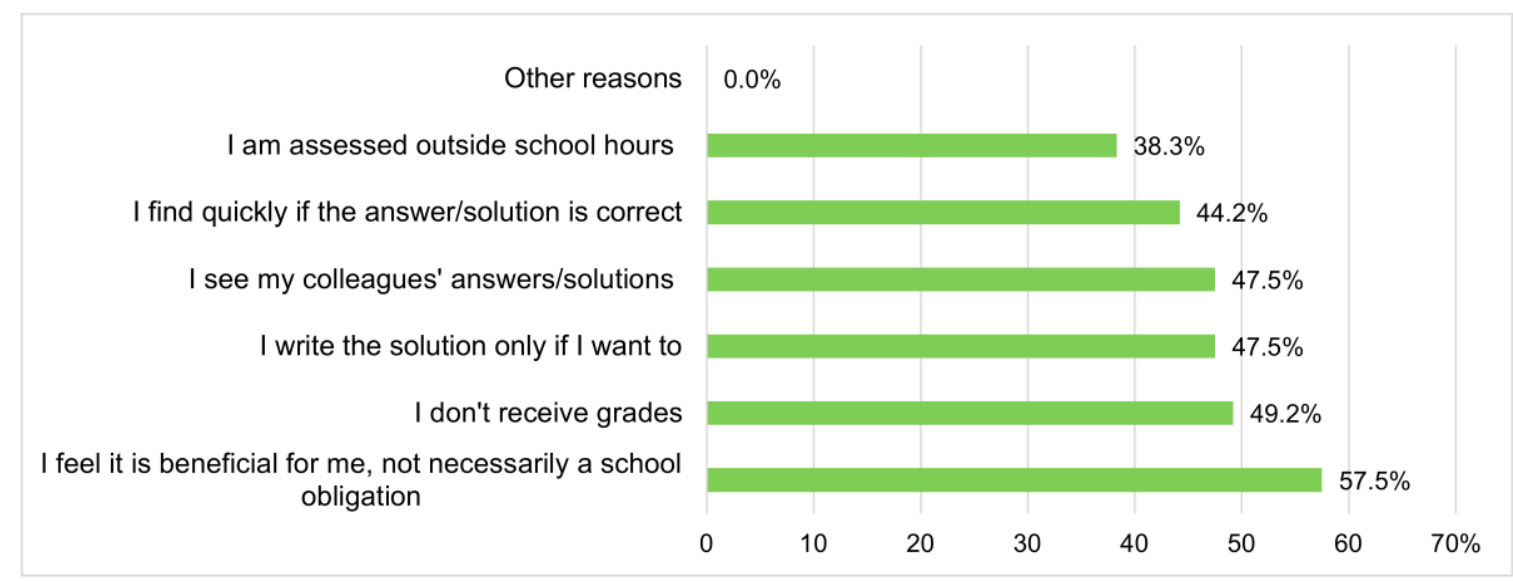

Fig. 12. Frequency of reasons why students liked to operate assessment activities in the Geography discussion group on Facebook

The analysis of activities developed in the Geography discussion group on Facebook

\section{a) Group organisation}

On the recommendation of the Geography teacher, in October 2015, the $12^{\text {th }}$ grade students created five Geography discussion groups on Facebook, one for each class. In these groups, they invited all colleagues to join, therefore all students got involved. Each group was closed for outside the classroom persons, except for the Geography teacher, so work was not visible to other Facebook users.

During the first discussion about the group, the teacher talked with students about the activities being carried out in the group and negotiated rules with students to achieve a consensus that everybody observed. These rules referred especially at communication. The literature said that students felt responsible for the rules that they created through negotiations with peers and teachers (Dulamă, 2008, p. 27). 


\section{b) The analysis of roles in the discussion groups}

The teacher had many responsibilities, some centred on keeping the group focused, and others paying attention to the cognitive processes. She was a participant who got directly involved into group work and an observer of cooperation, learning and assessment, of the group dynamics, of the work rhythm, of students' affinities, etc. She was a coordinator who provided the appropriate instruction frame through appropriate materials and procedures, by dosing time, through prescriptions given to students and through feedback. She announced future activities ("you won't do a test tomorrow, because we will study the hydrographical network") and scheduled additional learning activities ("you will learn in the practice week, when we can meet at the scheduled time.").

The teacher was a "motivator" because she stimulated students through tasks, through monitoring each group, through the presentation and evaluation of results, by activating certain purposes and interactive strategies, etc. She encouraged students who were absent for more than an hour to be mobilised to recuperate lessons ("come on, you have time to learn one more hour"). She was an instructor by giving students clear and precise instructions about how the group activity would develop and how they learnt at Geography. She was a consultant by giving students the necessary information to complete tasks and suggestions on solving problems. For example, if students confused the subunits of the Carpathian Mountains, she suggested: "try to achieve the subunits map of the Carpathians, by using the interactive board drawings that were saved on the group".

She was the facilitator because she helped students by providing materials, by asking questions, and by making sure that each student received support when needed. The teacher guided students to seek representative photographs of the some geographical terms ("Who will upload some pictures with the shores of Europe?" (Dalmatic type shore; fjord shore; shore with riass). She was the evaluator because she paid attention to the co-operation and discussions among students, she analysed answers and solutions to tasks.

Students' roles focused on maintaining the group, like the teacher (participant, observer, motivator, consultant, trainer, and facilitator). Some students had a coordinator role when the teacher delegated ("Cristina will be your teacher tonight because I still have some documents to do."). Students encouraged each other, invited their colleagues to study a site containing a soft about the Geography of Romania, addressed questions to colleagues, answered questions, argued, made announcements for Geography consultations and expressed written consent, provided feedback, posted various materials (sketch maps, photos, solved tests by themselves or by the others). 


\section{c) The analysis of using Facebook smileys and emoticons}

Many students like to express their moods and emotions using Facebook emoticons. They chose such symbols of more than 1,000 Facebook smileys and emoticons (list of emoticons for Facebook: http://www.symbols-nemoticons.com/p/facebook-emoticons-list.html). They used Facebook emoticons expressing positive emotions (the smile emoticon, the kiss smiley) or negative (the grin smiley, the frown emoticon). They remarked a student for associating various symbols when she addressed questions to

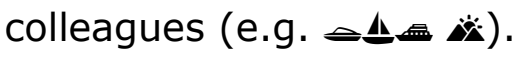

\section{d) The analysis of materials posted by teacher and students}

Students posted materials used in learning: landmass photographs, photos with hand-drawn sketch maps (made with a special pencil), maps (physical world map), and PowerPoint presentations. They posted materials for assessment: tests and quizzes created by themselves or by other people, printed items with solutions, and test solutions (written by hand on paper and photographed with the mobile phone). Some students invited their colleagues to study the educational software for the Baccalaureate exam (http://www.portalroman.com/diverse/rauri.php). A student posted the blackboard photo with the Geography consultations schedule activities for one week. Several students posted Geography jokes.

\section{e) The analysis of group dialogue}

Regarding dialogue initiation, in some cases, the teacher invited students to communicate, in other situations, students invited colleagues or the teacher to communicate with them. This behaviour indicated good co-operation between students and between students and the teacher, providing the basis for an effective communication. When students requested to dialogue with the teacher, they behaved in a proactive way ("Teacher, don't we have work this evening?").

Students addressed questions to the teacher, requiring clarification:

Student 1: What climate is in the Dobrudgea Plateau? For plains or for low hills?

Teacher: The low hills climate in the north, lowland climate in the southern part.

Student 1: I thought it is both (:) thank you Teacher ... even if it's hard to characterise them according to climate ... I am still trying to understand them

Student 1: In the Transylvanian Plateau is a climate of lower hills ... in some places, at $400 \mathrm{~m}$ and over $500 \mathrm{~m}$, it is high hills climate. Right? (:) 
Students asked the teacher similar test questions:

Student 1: Teacher, can you ask us some questions similar to the ones you'll ask during the test, please?

Student 1: Don't you want to ask one another?

Student 2: We will do that later tonight, when there are more people online.

Student 3: I say at 12 ("night"). Then everybody will be online (:)

Student 4: Anybody willing to answer new questions?

Teacher: ... starting from 17:00 until then, repeat *

The teacher issued various tasks and questions for students:

Teacher: What is the highest altitude in the central group of the Eastern Carpathians?

Teacher: specific relief type of Bucegi group ...

Teacher: relief on conglomerates, "Babele" (old women) and the "Sphinx"

Teacher: two similarities between the central group of the Eastern Carpathians and the Apuseni Mountains group

Teacher: How is the foundation of the Eastern Europe Plain called???

Teacher: Which is the lowest relief unit in Europe?

Students asked various questions to colleagues, many of them targeting specific data:

\section{November 9, 2015 at 7:26 p.m. to 7:54 p.m.}

Student 1: So I will ask many questions and wait five minutes to answer, after that I'll write the next question...

Student 1: What kind of plain is the North European Plain... What was the..????

Student 2: River-glacial accumulation - that was heavily shaped by the ice cap?

Student 1: The Ural Mountains have a length of ...? The highest altitude is....? They belong to what orogenesis?

Student 3: The Hercynian orogenesis, 2,000 km length, the highest altitude $1,895 \mathrm{~m}$

Student 1: What orogenesis are the Alps Mountains part of???

Student 4: the Alpine

Student 1: The altitude of the Bârlad Plateau is? ? 
Student 5: 400-500 m

Student 1: Which is the only navigable arm of the Danube Delta??? 年息

Student 4: Sulina

Student 1: The limits of the Western Carpathians???

Student 6: The Danube Valley-S, the Barcăului Valley and the Someş Valley-N

Student 1: What is the highest peak of the Carpathians?

Student 8: Pietrosu Rodnei Peak 2,303m

Student 1: What kind of relief do the Meridional Carpathians have??

Student 5: Glacial

Student 1: List the subdivisions of the Moldova Plateau I)

Student 7: The Suceava Plateau, the Bârlad Plateau, the Moldova Plain

Student 1: Conditions of the Delta formation???

Student 2: Large alluvial river flow, lack of tides, low speed spill, sedimentary material brought by sea.

Student 5: Large alluvial river flow, low speed spill, sedimentary material brought by sea, lack of tides.

Student 8: low speed spill; lack of tides; high flow of silt

\section{January 27 at 9:40 p.m. to 9:52 p.m.}

Student 1: Thank you, Teacher, that you proposed me!

Student 2: Until the Teacher gets in I say we should ask one another ...

Student 2: A volcanic lake?

Student 3: St. Anne...

Student 2: What is the originality of the Black Sea?

Student 1: Lack of vertical currents

Student 2: Yes, I'll ask 3 more questions, then somebody else will, ok?

Student 3: What are the limits of the Carpathians?

Student 1: In north, the border with Ukraine and in south Prahova Valley

Student 1: Ok.

Student 2: In N, the border with Ukraine, and in S, Prahova Valley

Student 3: Bravo girls :))))

Student 1: :))

Student 2: What rocks are abundant in in the Eastern C.?

Student 1: Volcanic 
Analysing Facebook group conversation we noticed that for increasing the online communication speed, they used abbreviations for words and sentences and there was no care for spelling (lack of diacritics) and punctuation. These were features of the written language for the Internet communication. This kind of communication focused on message transmission and understanding, not on its form. Unlike the virtual environment, in the classroom, teachers accepted only a correct grammatical language in writing on the black board, tests, and homework. We noticed also that students perceived the teacher's presence in the discussion group as a factor that influenced their freedom of expression. This study did not aim at analysing the involvement frequency of each person into the group discussion. Nevertheless, it appeared that students were more involved before tests.

\section{CONCLUSIONS}

For Geography learning and assessment using discussion groups on Facebook, teachers should have initiative and readiness to allocate time resources for such informal activities. Regarding students, they were engaged in group activities during the time spent at home, usually in the evening, after they had completed other learning activities, and during the semester, before tests.

Unlike the formal class activities, work in discussion groups was optional, each group member having the opportunity to be active or a viewer. Learning and assessment activities done within a social network were perceived positively because, except emoticons, there were no penalties for mistakes. Unlike during Geography classes, where the teacher had an official position, in Facebook discussion groups, the teacher was perceived as an ordinary participant. Even if the teacher and the students used temporarily, in this virtual environment, a language less censored by the grammar rigours, in the official school environment they readjusted the speech to the context.

At the cognitive level, the activity was focused on clarifying certain aspects, revision, learning and assessment of various knowledge types, being influenced by the Geography baccalaureate subjects. Even if some students seemed not to be active, but curious viewers, they evaluated themselves and strengthened their knowledge.

To increase the development quality of Geography specific competences useful in life and less tested on the Baccalaureate exam, one should propose more applications for the discussion group. The biggest 
disadvantages of the learning activity in the Facebook discussion group was that the posted materials could not be classified and could be found with difficulty when students needed to revise them. To solve this deficiency, students downloaded materials in their computers.

\section{REFERENCES}

Acquisti, A., \& Gross, R. (2006). Imagined Communities: Awareness, Information Sharing, and Privacy on the Facebook. Privacy Enhancing Technologies, 4258, 36-58.

Dulamă, M.E. (2008). Metodologii didactice activizante. Cluj-Napoca: Editura Clusium.

Dulamă, M.E., Ilovan, O.-R., Ciascai, L., \& Maroşi, Z. (2015a). E-learning Geography. How Powerful Is Facebook for Geography University Students? In Vlada M., (ed.), Proceeding of the $10^{\text {th }}$ International Conference on Virtual Learning (pp. 121-127). Bucureşti: Editura Universitatii din Bucureşti.

Dulamă, M.E., Magdaş, I., \& Osaci-Costache, G. (2015b). Study on Geography Students' Internet Use. Romanian Review of Geographical Education, IV(1), 45-61.

Ellison, N.B., Steinfield, C., \& Lampe, C. (2007). The Benefits of Facebook "Friends:" Social Capital and College Students' Use of Online Social Network Sites. Journal of Computer-mediated Communication, 12(4), 1143-1168.

Grosseck, G., Bran, R., \& Tiru, L. (2011). Dear Teacher, What Should I Write on My Wall? A Case Study on Academic Uses of Facebook. Procedia - Social and Behavioral Sciences, $3^{\text {rd }}$ World Conference on Educational Sciences, Elsevier, $15,1425-1430$.

Hew, K.F. (2011). Students' and Teachers' Use of Facebook. Computers in Human Behavior, 27(2), 662-676.

Junco, R. (2012). The Relationship between Frequency of Facebook Use, Participation in Facebook Activities, and Student Engagement. Computers \& Education, 58(1), 162-171.

Madge, C., Meek, J., Wellens, J., \& Hooley, T. (2009). Facebook, Social Integration and Informal Learning at University: 'It Is More for Socialising and Talking to Friends about Work than for Actually Doing Work'. Learning, Media and Technology, 34(2), 141-155.

Osaci-Costache, G., Cocoș, O., \& Cocoș, A. (2014). Online Cartographic Materials for Geographical Higher Education: Opportunity or Threat? In Vlada, M., Albeanu, G., \& Popovici, D. M. (eds.), Proceedings of the $9^{\text {th }}$ International Conference on Virtual Learning ICVL 2014, Bucharest, 24-25 October 2014, (pp. 218-224). Bucureşti: Editura Universității din București.

Pempek, T. A., Yermolayeva, Y. A., \& Calvert, S. L. (2009). College Students' Social Networking Experiences on Facebook. Journal of Applied Developmental Psychology, 30, 227-238. 
Roblyer, M.D., McDaniel, M., Webb, M., Herman, J., \& Witty, J.V. (2010). Findings on Facebook in Higher Education: A Comparison of College Faculty and Student Uses and Perceptions of Social Networking Sites. Internet and Higher Education, 13, 134-140.

Socialbakers (2011). Facebook Statistics by Country. Retrieved 22 January 2016, from http://www.socialbakers.com/statistics/facebook/pages/total/romania/

Demographic data Facebook Romania. Retrieved 22 January 2016, from http://www.facebrands.ro/demografice.html

Facebook map users in Romania. Retrieved 22 January 2016, from http://www.facebrands.ro/demografice.html 